\title{
Postoperative Delirium in a General Surgery- Geriatric Medicine Service
}

\section{Dr. Si Ching LIM, MB. ChB, MRCP ${ }^{1}$, Dr. Peter CHOW, MB. ChB (CUHK), MRCP, FAMS ${ }^{2}$ Zhang Di $^{3}$, Swee Sim HIEW ${ }^{4}$, Adrian JH Koh, MBBS, FRCS (Edin) FRCS (Glas) ${ }^{5}$}

\author{
${ }^{1}$ Adjunct Associate Professor, Senior Consultant, Department of Geriatric Medicine, Changi General Hospital, \\ Singapore. \\ ${ }^{2}$ Consultant, Department of Geriatric Medicine, Changi General Hospital, Singapore. \\ ${ }^{3}$ Advanced Practice Nurse (Geriatric Medicine), Changi General Hospital, Singapore. \\ ${ }^{4}$ Senior Nurse Manager, Changi General Hospital, Singapore. \\ ${ }^{5}$ Adjunct Associate Professor, Senior Consultant General Surgery, Changi General Hospital, Singapore. \\ si_ching_lim@cgh.com.sg \\ *Corresponding Author: Dr. Si Ching LIM, MB. ChB, MRCP, Adjunct Associate Professor, Senior Consultant, \\ Department of Geriatric Medicine, Changi General Hospital, Singapore.
}

\section{Abstract}

The vulnerable elderly surgical patients are susceptible to complications in the perioperative period. The elderly have limited reserve and in the perioperative period, multiple insults are added in addition to the injuries incurred by surgery. Postop delirium is common among the frail elderly especially among those with background cognitive impairment and poor function. Postop delirium is associated with poor outcome in the short and long term.

Keywords: postop delirium, drugs, restraints use, dementia.

\section{INTRODUCTION}

Singapore is rapidly ageing and the elderly admitted under Department of General Surgery for both elective surgeries as well as emergency surgeries will likely increase over the years. The hospitalized elderly are vulnerable to develop complications associated with hospital stay, particularly iatrogenic complications, delirium, restraint use, falls, malnutrition and functional decline. These adverse effects may occur immediately since the time of admission. (1)

Among the elderly patients admitted for surgical care, perioperative complications are directly associated with poor outcome and the risk increases with advancing age. Perioperative complications among among patients aged $>80$ have a $25 \%$ greater 30 -day mortality, compared to the uncomplicated elderly. Delirium in the postoperative setting may occur in up to $50 \%$ of elderly patients, and is associated with increased mortality, longer hospital stays, cognitive and functional decline. The elderly patients are at higher risk of developing delirium, and delirum is often overlooked it is often overlooked in hospitalized patients. $(2,3)$

\section{AIM OF THE STUDY}

The aim of the study was to identify incident delirium among the elderly postoperative patients and to encourage early referrals to the Geriatricians for early intervention and improve overall outcome during the hospital stay.

\section{METHOD}

This is a prospective study with data collection for the elderly surgical patients aged over 65 , referred by the department of General Surgery who screened positive for delirium in the postoperative period. There were 27patients who were referred during a six month period. The study began with educating the nurses and doctors in the department of General Surgery on the clinical features of delirium, screening for delirium using CAM, early diagnosis and interventions to improve recovery. All the referrals were assessed by a geriatrician, together with a Geriatric trained nurse and medications were assessed by a pharmacist with special interest in Geriatric pharmacology. All the postoperative delirious patients were subsequently 
either taken over by the Geriatrician or closely co-managed until they were discharged from the hospital.

\section{RESULT}

There were a total of 27 patients referred to the Geriatricians. The mean length of stay was 28 days (range 5-95 days). There were 6 patients who were readmitted within 30days of discharge.These readmissions were not planned admissions. The mean age was 82 years old. Thirty-six percent of the patients underwent elective surgeries.

Two thirds of the elderly patients with delirium had background history of dementia. Eighty percent (80\%) required assistance in Instrumental Activity of Daily Living (IADL). The Barthel Index was used to assess the basic activities of daily living (BADL). The mean score for Barthel Index was 18.5, out of 20 , with $63 \%$ requiring some assistance with their BADLs.

Postoperative delirium occurred within the first 3 postoperative days among 64\% of the elderly. During the assessment by geriatricians and pharmacist, $80 \%$ of patients were complaining of pain most part of the day, 15 patients (55\%) were given medications with anticholinergic properties among which include metoclopramide, tramadol, pethidine, hydroxyzine, chlorphenaramine and paracetamol /orphenadrine combination. Sepsis, as indicated by fever or raised inflammatory markers were present in $63 \%$ of the patients. Indwelling urinary catheters were in situ among $60 \%$ of patients, with 3 patients who developed acute urinary retention during the perioperative period. All the delirious elderly surgical patients had constipation, which was defined as no bowel output for at least 3 days.

Mixed hyper and hypoactive delirium was the commonest type, present among $63 \%$ of the patients, $22 \%$ had hyperactive delirium and $15 \%$ had hypoactive delirium. Consequently, 64\% were restrained physically, $12 \%$ had chemical restraint with antipsychotic and the remaining had both physical and chemical restraints on board to manage their behaviour symptoms.

\section{Discussion}

There is the vulnerability factor to consider why delirium develops in certain elderly. The onset of delirium is often due to insults on an individual with a variety of predisposing factors such as older age, low education level, multiple comorbid diseases, background history of dementia, history of previous episode of delirium, sensory impairment and impaired function. The more risk factor an elderly has, the higher the risk of developing incident delirium during their hospital stay. The precipitating factors are acquired after hospitalization and these include physical restraints, malnutrition, iatrogenic event, medications and indwelling urinary catheter. Delirium is associated with prolonged hospital stay, mortality, falls, incontinence, nursing home placement and long term cognitive decline. The elderly with high vulnerability factor need only trivial insults to precipitate an episode of delirium. $(4,5)$ Delirium can be present in up to $50 \%$ of the postop patients in the surgical wards. The onset of postoperative delirium is typically within day 1-3 postop, later onset delirium is often associated with other complications like alcohol withdrawal, new hospital acquired infections, electrolyte disturbance or drugs. $(6,7)$

In the sample of postop delirium surgical patients $>65$ years old, the commonest factors which contributed to delirium were poor pain control, drugs, ongoing sepsis, indwelling catheter and constipation.Premorbidly, only 5 patients were community ambulant and $80 \%$ of the patients with incident delirium needed assistance with their activities of daily living (ADL). Needing assistance with their ADLs indicates high vulnerability to develop delirium because of their poor functional reserve. The use of urinary catheter is a known precipitating factor for delirium as it causes immmobilsation and increases infection risk. (4)

The relationship between delirium and dementia is well documented. The onset of delirium under stressful condition suggests reduced cognitive reserve and the patients are at risk for future episodes of delirium. Delirium does not always lead to complete resolution with return of premorbid cognitive function, particularly among those with prolonged delirium. Among patients with Alzheimer Disease, delirium is associated with accelerated rate of cognitive decline. $(5,8)$ Delirum and dementia frequently co-exist and dementia is the leading risk factor for delirium (4) Delirium may be a risk factor for dementia eventhough neuropathological association was not consistently shown. (9) In this study group, diagnosis of dementia as a co-morbidity was documented in $2 / 3$ of the patients, which is probably an under-estimate. In this local culture, diagnosis of dementia is often delayed 
as the cognitive problems are blamed on ageing. Early diagnosis of dementia is important to educate the patient and family, provide treatment, screen for and manage behavioural symptoms, referral for social services, counselling for advance medical directives, end of life care and participate in research activities. (10)Longer term follow up with repeat assessment of cognition will be useful to track the long term outcome of postop delirium among this group of vulnerable elderly.

The culprit drugs identified included those with anticholinergic properties, long acting opioids such as pethidine, prescription of multiple opioids or intrathecal opioids. Most post-operative patients would have pain from the surgical wound, tissue injuries and various lines and drains. Undertreated pain among the postoperative elderly hip fracture patients has been well described to be associated with a nine time higher risk of developing delirium. (11) Drugs with anticholinergic properties are commonly used and the prescribers are often not aware of the potential harm for the elderly patients. Delirium has been linked to central cholinergic deficiency. The combined usage of drugs with anticholinergic properties, measured using defined daily dose, is associated with delirium severity in a dose-responsive way. Delirium severity among the the ill elderly taking medications with anticholinergic properties is independent of background dementia. (12) Anticholinergics usage among the elderly are strongly discouraged according to the Beers Criteria. The anticholinergic side effects such as constipation, urinary incontinence, dry mouth and delirium are among the commoner adverse effects seen clinically. The ageing brain is also more vulnerable to anaesthetic agents, resulting in increasing drowsiness in the postop period and delirium risk particularly for long surgeries. (13) The anticholinergic drugs which were commonly used among the delirious elderly surgical patients in the study included off label use of first generation antihistamines prescribed as night sedation, antiemetic such as metoclopramide was widely prescribed together with opioids in anticipation of emesis induced by opioids and a combination drug which contains paracetamol plus orphenadrine which were prescribed for its analgesic and muscle relaxant property. For the management of delirium, the first line strategy is discontinuation or dose reduction of drugs with anticholinergic properties and psychotropic drugs. For the elderly hospitalised patients, polypharmacy is a common occurrence and identification of culprit drugs is important for early intervention. (5) The General Surgery Geriatric service has a pharmacist in the team who is trained in geriatric pharmacology who assisted the medical team in medication prescribing.

Post-operative elderly patients are prone to develop infection due to surgical instrumentation, poor nutrition, immunesenescence and immobility. Constipation, retention of urine and use of indwelling catheter were common in the postop period and may all contribute to immobility, delirium and discomfort. The causes for postop poor nutrition and constipation are often multiple and additive, such as drugs, immobility, pain limiting movement, poor oral intake, postop ileus or patients being kept on nil by mouth to rest the gastrointestinal (GI) tract after complicated GI surgeries. In the study population, all of them had constipation. The Enhanced Recovery After Surgery (ERAS) protocol discourage prolonged period of resting the GI tract in the post op period and encourage early mobilisation with early oral nutritional intake in the postop period to reduce some of these complications. (14)

The diagnosis of delirium is difficult and up to $50 \%$ is missed. (15) There are psychomotor changes associated with delirium, with hyperactive, hypoactive and mixed types. The hypoactive type is often missed since patients are lethargic, apathetic and drowsy. The hyperactive type is described as combative, restless, irritable and agitated. (16) In the study, the delirious patients were often put on physical restraints and or chemical restraints to manage their agitation and restlessness in order to avoid injuries to themselves/ others or attempting to pull out medical equipment. Restraints aim to reduce their freedom of movement and in doing so, often causes more harm than benefits. Physical restraints have not been convincingly shown to reduce falls in the hospital among the elderly. Enforcing immobility among the frail elderly may lead to constipation, pressure sores, poor appetite, functional decline, incontinence, delirium, cognitive decline which prolong the hospital stay. (17)

Even though the study population was small, the emphasis of drugs as major contributing factors to delirium must be stressed. There were probably more cases of postop delirium which was not picked up by the surgical ward nurses or the surgeons and were discharged home. It was interesting that 36\% of the patients who developed delirium post op were 
Postoperative Delirium in a General Surgery- Geriatric Medicine Service

elective cases. There is currently no routine preop assessment by the geriatricians and this is probably a worthwhile project to pursue in order to identify risk factors and intervene in the perioperative period before delirium develops. The involvement of geriatricians in the assessment of surgical patients is now given increasing attention since it is important to pick up nutritional issues, frailty, cognitive problems, depression, optimisation of comorbidities and functional issues preoperatively as these factors have an impact on postop outcome, both in the short term physical recovery and return of function to premorbid level as well as the long term outcome. (17)

Table 1. Postoperative Delirium

\begin{tabular}{|c|c|}
\hline Gender & Male $=17$, Female $=10$ \\
\hline Age range & Mean $82(66-94)$ \\
\hline Type of surgery & $\begin{array}{l}\text { Hepatobiliary }+ \text { Pancreas }=9 \\
\text { Upper GI }=7 \\
\text { Colorectal }=5 \\
\text { Vascular }=3 \\
\text { Others- general surgery }=2, \text { Ortho }=1\end{array}$ \\
\hline $\begin{array}{l}\text { Onset of delirium (from postop } \\
\text { day) }\end{array}$ & $\begin{array}{l}0=2 \\
\text { Day } 1=17 \\
\text { Day } 2-4=4 \\
\text { Day } 10 \text { and beyond= } 4\end{array}$ \\
\hline Electrolyte abnormalities & $\begin{array}{l}\text { Hyponatraemia }=11 \\
\text { Hyperglycaemia }=6 \\
\text { AKI }=6 \\
\text { Acidosis }=4 \\
\text { Others }=\text { hypokalaemia, hypocalaemia, hypo PO4 } \\
\text { No electrolyte abnormalities }=3\end{array}$ \\
\hline $\begin{array}{l}\text { Medical issues contributing to } \\
\text { delirium }\end{array}$ & $\begin{array}{l}\text { Constipation (no BO } \geq 2 \text { days) }=26 \\
\text { Fluid overload }=5 \\
\text { Poor oral intake }=5 \\
\text { NSTEMI }=5 \\
\text { Hb drop }>2 g=4\end{array}$ \\
\hline Drugs & $\begin{array}{l}15 \text { had been given drugs with anticholinergic properties- maxolon, anarex, } \\
\text { cough syrup, antihistamines, pethidine. Alcohol withdrawal=1 }\end{array}$ \\
\hline Pain & $\begin{array}{l}\text { Inadequate pain control= } 21 \\
\text { No complaints of pain }=6\end{array}$ \\
\hline
\end{tabular}

\section{CONCLUSION}

The frail perioperative surgical patients have an increased risk of developing complications in the hospital, among which postop delirium is probably the commonest and is potentially preventable. The causes of postop delirium are multiple and identification of predisposing factors and anticipating complications postoperatively. Delirium carries with it long term consequences like poor functional outcome, progressive cognitive decline and risk of institutionalisation. intervention should begin preoperatively with 
Postoperative Delirium in a General Surgery- Geriatric Medicine Service

\begin{tabular}{|c|c|}
\hline Sepsis & Related to surgery or hospital acquired= 17 \\
\hline Indwelling urinary catheter & Present $=16,3$ were inserted for ARU \\
\hline Hx of dementia & $\begin{array}{l}\text { Positive in } 18 \\
9 \text { not known to have dementia }\end{array}$ \\
\hline Depression & Positive $=2$ both in presence of dementia. \\
\hline $\begin{array}{l}\text { Premorbid Instrumental } \\
\text { activities of daily living }\end{array}$ & $\begin{array}{l}\text { Independent }=5 \\
\text { Assisted }=22\end{array}$ \\
\hline $\begin{array}{l}\text { Premorbid Activities of daily } \\
\text { living }\end{array}$ & $\begin{array}{l}\text { Independent }=10 \\
\text { Assisted }=17\end{array}$ \\
\hline Types of delirium & $\begin{array}{l}\text { Hypoactive delirium }=4 \\
\text { Hyperactive delirium }=6 \\
\text { Mixed hypo and hyper active }=17\end{array}$ \\
\hline Restraint use & $\begin{array}{l}\text { Physical restraint }=16 \\
\text { Chemical restraint }=3 \\
\text { Physical+ chemical restraint }=2\end{array}$ \\
\hline
\end{tabular}

\section{REFERENCES}

[1] Walsh KA et al. Review: Hospitalization and the elderly. Ann Long Term Care 2007; 15: 18-23.

[2] Frederick ES. Preventing postoperative complications in the elderly. Anaesthesiol Clin 2011 March; 29(1): 83-97.

[3] Hamel MB et al. Surgical outcomes for patients aged 80 and older: Morbidity and mortality from major noncardiac surgery. J Am GeriatrSoc 2005; 53(3): 424-429.

[4] Sharon K Inouye et al. Precipitating factors for delirium in hospitalized elderly persons. JAMA Mar 201996 Vol 275.

[5] Inouye SK. Delirium in elderly persons. The Lancet 2014;383: 911-22.

[6] Spronk PE, Riekerk B, Hofhuis J, Rommes JH. Occurrence ofdeliriumisseverelyunderestimated in the ICU during daily care. Intensive Care Med 2009; 35: 1276-80

[7] Litaker D et al. Preoperative risk factors for postoperative delirium. Gen Hosp Psych 23(2001):84-89.

[8] Gross AL et al. Delirium and long term cognitive trajectory among persons with dementia. Arch Intern Med 2012; 172:1-8.
[9] Daniel H Davis et al. Delirium is a strong risk factor for dementia in the oldest-old: a populationbased cohort study. Brain Volume 1, issue 9, 1 sept 2012, 2809-2816.

[10] Jeffrey L Cummings et al. Guidelines for managing Alzheimer's Disease: Part I. Assessment. American Family Physician June 1,2002/Volume 65, Number 11.

[11] R. Sean Morrison et al. Relationship between pain and opioid analgesics on the development of delirium following hip fracture. The Journal of Gerontology: series A, Vol 58, Issue 1,1jan 2003, pM76-81.

[12] Ling Han et al. Anticholinergic drug burden predicts delirium severity among older medical patients under intensive care. Alzheimer's \& Dementia 2016. Vol 12, issue 7 supplement pp803.

[13] American Geriatric society 2015 updated Beers Criteria for potentially inappropriate medication use in older adults. By the American geriatric Society 2015 Beers Criteria Update Expert Panel. JAGS 63:2227-2246, 2015.

[14] KCH Fearon, Ljungqvist O, Von Meyenfeldt M, Revhaug A, Dejong CH, et al. (2005) Enhanced recovery after surgery: A consensus review 
Postoperative Delirium in a General Surgery- Geriatric Medicine Service

of clinical care of patients undergoing colonic resection. Clin Nutr 24(3): 466-477.

[15] Milisen $\mathrm{K}$ et al. Documentation of delirium in elderly patients with hip fracture. J GerontolNurs 2002;28:23-9.

[16] Marcantonio E et al. Delirium severity and psychomotor types: their relationship with outcomes after hip fracture repair. J Am geriatrSoc 2002;50:850-7.
[17] Lim SC, PoonWH. Restraintusein themanagement of the elderly with dementia in hospital. Internal Med Res Open J. Volume 1(2): 1-4, 2016.

[18] Warren B, Chow wt al. Optimal preoperative assessment of the geriatric surgical patient: A best practices guideline from the American College of Surgeons National Surgical improvement Program and the American Geriatric Society. J Am CollSurg Vol 215, No 4, October 2012.

Citation: SC Lim, Peter CL Chow, Zhang Di, SS Hiew, Adrian JH Koh. Postoperative Delirium in a General Surgery- Geriatric Medicine Service. Open Journal of Geriatrics. 2018; 1(1): 15-20.

Copyright: (C) 2018 SC Lim, Peter CL Chow, Zhang Di, SS Hiew, Adrian JH Koh. This is an open access article distributed under the Creative Commons Attribution License, which permits unrestricted use, distribution, and reproduction in any medium, provided the original work is properly cited. 